\title{
Inequality, Social Networks, and Internet Use: Exploring the Implications of the Social Diversification Hypothesis
}

\author{
Eric Tsetsi \& Stephen A. Rains
}

University of Arizona

Social networks and their implications have been a longstanding topic of interest among communication scholars (Hargittai, 2007; McDermott, 1980; Mutz, 2002; Rogers \& Kincaid, 1981; Valenzuela, Park, \& Kee, 2009). Indeed, the size and composition of one's social network is integral to one's well-being and access to social resources (Campbell, Marsden, \& Hurlbert, 1986; Eagle, Macy, \& Claxton, 2010; Lin, 2000). Scholars have pointed out, however, that there are substantial structural obstacles traditionally disadvantaged groups face that impose limits on their networks (DiMaggio \& Garip, 2011). Recent research suggests Internet use may allow disadvantaged groups to overcome some of these obstacles (Gonzales, 2015; Mesch, 2007, 2011, 2017; Mesch \& Talmud, 2010; Smith, 2013; Tsetsi \& Rains, 2017). The social diversification hypothesis (SDH) offers one explanation for this phenomenon, predicting that disadvantaged groups are motivated to use the Internet and social applications (e.g., social network sites [SNSs], blogs, online communities) to expand and diversify their social networks, while advantaged groups instead use these tools to maintain their existing networks (Mesch, 2011). Through developing larger, more diversified personal networks via the internet, disadvantaged groups might increase their access to non-redundant information thus increasing social capital and allowing them to overcome social inequality (Mesch, 2011). Although evidence consistent with the SDH has been reported in several studies (Gonzales, 2015; Mesch, 2007, 2011, 2017; Mesch \& Talmud, 2010), the implications of Internet use for network-based inequalities warrant further attention.

The SDH is fundamentally concerned with the different motivations for Internet use exhibited by disadvantaged and advantaged populations in multicultural societies (Mesch, 2011). A gap in SDH research, however, exists in regard to whether or not these underlying motivations result in a measurable leveling of network-based inequalities in terms of network size and composition. The present study fills this gap in research and seeks to advance the SDH by examining the implications of Internet and SNS use for the composition of advantaged and disadvantaged groups' social networks. Inequalities explored in the present study regard the disparities in the number of people individuals can share important matters with (i.e., core network), how many people they know (i.e., kin network and total network), and the diversity of their networks in terms of the proportion of kin, political attitudes, and socioeconomic status of network members. We test the 
key outcomes predicted by the SDH (Mesch, 2007, 2011, 2017; Mesch \& Talmud, 2010) and broaden its theoretical scope by investigating whether network-related inequalities distinguishing traditionally disadvantaged groups (i.e., non-Whites, women, and less educated individuals) from their more advantaged counterparts (i.e., Whites, men, and higher educated individuals) differ between non-Internet users, Internet users, and Internet plus SNS users.

In order to test the outcomes proposed by the SDH, we used a dataset from a 2010 Pew Research Center study. In addition to including nuanced measures of several social network variables among a national sample of U.S. adults, the timing of this cross-sectional survey made it possible to acquire sizeable groups of Internet users who did and did not participate in SNSs. In the last decade, the Internet and the activities people perform on the Internet have evolved along with the technologies people use to connect online (e.g., smartphones and tablets). Only about $45 \%$ of U.S. adults used SNSs in 2010 compared to $72 \%$ in 2019 (Pew Research Center, 2019). This dataset, therefore, provides a historical context in which we can go beyond blunt differences in Internet users and non-users and evaluate the unique implications of SNS use. In the following sections, we first discuss inequality in social network composition and then detail the SDH framework (Mesch, 2007, 2011, 2017).

\section{Literature Review}

\section{Inequality and Social Networks}

Inequality has been conceived of as asymmetrical access to resources in a social system (Lin, 1999, 2000). In the context of social networks, resources represent information communicated through an individual's connections (Granovetter, 1973; Lin, 1999, 2000). Additionally, network structure (e.g., location within a network) facilitates access to such resources (Lin, 1999, 2000). The concept of social capital (Bourdieu, 1985; Coleman, 1988; Lin, 1982; Putnam, 2000) is rooted in the idea that the relationships and structure of one's social network are important for accessing valuable resources (Coleman, 1988). The two core elements of social capital, according to Coleman (1988) are trustworthiness and obligations, such that when trustworthiness is high, people can expect social obligations to be repaid, and the amount of obligations one is owed constitutes their social capital. The stronger, broader, and more varied one's network connections, the more of these resources that are likely to be available in times of need (Lin, 1999, 2000). Network connections can take two primary forms. Social capital is built not only through the number of bridging ties (i.e., weak ties) one has, but also through the strength of one's bonds (i.e., strong ties; Granovetter, 1973). Whereas bonding ties involve family and close friends, bridging ties refer to distant others like acquaintances. Bridging ties, which are more easily accessible via the Internet (Mesch, 2011; Hargittai \& Hsieh, 2010), are important because they can link networks and thus provide access to expanded resources. It should also be noted that researchers have proposed an alternative "enclave hypothesis," which suggests that some racial and ethnic minorities find strength in densely-knit communities defined by their homogeneity and strong ties (Portes \& Jensen, 1989). The SDH, however, 
specifically focuses on bridging ties (i.e., ties the link disparate groups) as a way for disadvantaged groups to overcome inequality in social networks.

Lin (2000) identified two fundamental reasons why groups have unequal access to social capital. The first is that certain groups face structural inequalities that leave them with fewer resources. Different groups distinguished by race, sex, and education exhibit structural disadvantages in terms of socioeconomic standing that arise from cultural or societal norms (Lin, 2000). The second reason is that groups tend to cluster with similar others (i.e., homophily; for a review, see McPherson, Smith-Lovin, \& Cook, 2001). Homophily is important because disadvantaged groups tend to form networks with similar disadvantaged others thus leaving the entire network with fewer resources compared to advantaged groups. In other words, those in advantaged networks not only benefit from the quantity of resources available in their networks, but also from a diversity of resources (Lin, 2000).

Network-based inequalities are particularly relevant for non-Whites, women, and the less educated who are negatively affected by factors including group size relative to majority groups, cultural and societal norms, and fewer opportunities for advancement among other factors (McPherson et al., 2001). Studies show that network size and composition are associated with demographic characteristics (for a review, see Marsden, 1987). For example, women have traditionally exhibited a higher proportion of kin relationships in their core networks while men have larger non-kin networks (Marsden, 1987; McPherson et al., 2001; Moore, 1990). Having a higher proportion of kin in one's core network results in more homogenous networks, which restricts diversity (Coleman, 1988; Marsden, 1987). These associations may be in part explained by women's role as primary caregivers, which has also been found to negatively relate to women's total network size (Munch, McPherson, \& Smith-Lovin, 1997). Another factor is that men and women participate in different organizations that have different levels of embedded resources (Lin, 2000). More recent research on network inequalities, however, showed no significant difference in the proportion of non-kin relationships between men and women (McPherson, Smith-Lovin, \& Brashears, 2006). Thus, this specific network inequality may be changing. The present study hopes to shed additional light on this difference.

Whites also exhibit significantly different networks than Blacks and Hispanics (Hogan, Hao, \& Parish, 1990; Lin, 2000; McPherson et al., 2001; Moore, 1990; Parks-Yancy, DiTomaso, \& Post, 2009). Both Blacks and Hispanics report significantly smaller and less diverse networks compared to Whites (Marsden, 1987; McPherson et al., 2006). Homophily and structural factors (e.g., residential segregation, group size) have been proposed as partial explanations for these trends (Lin, 2000; Marsden, 1987; McPherson et al., 2001).

Education is another robust predictor of network structure (McPherson et al., 2001). Education is positively associated with network size and diversity such that the more education one has the larger and more diverse one's network tends to be (Marsden, 1987; McPherson et al., 2006). These trends are likely due to both structural constraints (e.g., decreased organizational affiliations) and homophily. Mardsen (1987), for example, explains that, "Education is associated with larger, more varied networks providing access to diverse others" (p. 129). In other words, 
the size and diversity of higher educated individuals' networks are products of increased bridging ties and less network density (Marsden, 1987).

In the present study, we examine the implications of race, sex, and education for two dimensions of network size and three measures of network diversity. Regarding network size, we consider an individual's core network (Marsden, 1987) and the total number of others an individual knows (McCarty, Killworth, Bernard, Johnsen, \& Shelley, 2001). Core network size is important because it reflects the number of strong or bonding ties someone has (i.e., the individuals one can discuss important matters with), while the total number of people someone knows is important for measuring the extent of one's network. Together, these network size measures help clarify the structure of one's network by identifying both the bonding ties and the bridging ties one maintains. We examine network diversity in terms of the proportion of non-kin in one's core network, the ideological diversity in one's core network, and the socioeconomic diversity among members of one's total network (Lin \& Erickson, 2008). Network diversity is important because it increases trust and tolerance in others and decreases the echo chamber effect that restricts people from questioning their own ideological beliefs (Coleman, 1988; Jamieson \& Capella, 2008). Occupations also vary in the resources they provide access to such that knowing people in a range of positions offers access to greater social capital (Lin \& Erickson, 2008). In sum, larger and more diverse networks are associated with greater social capital.

Following previous research (Lin, 1999, 2000; Marsden, 1987; McPherson et al., 2001; Moore, 1990; Rains \& Tsetsi, 2017), we predict women will have larger core networks, smaller overall networks, and less diverse networks in terms of the proportion of non-kin connections, perceived political diversity, and socioeconomic diversity than those of men. Non-Whites will have smaller core networks, smaller overall networks, and less diverse networks in terms of the proportion of non-kin connections, perceived political diversity, and socioeconomic diversity than those of Whites (Lin, 1999; 2000; Marsden, 1987; McPherson et al., 2001; McPherson et al., 2006). Finally, we expect that less educated individuals will exhibit smaller core networks, smaller total networks, and less diverse networks (i.e., smaller proportion of non-kin, less perceived political diversity, and less socioeconomic diversity) than more educated individuals (Marsden, 1987; McPherson et al., 2006).

Hypothesis 1 (H1): Compared to Whites, non-Whites will report (a) smaller core networks, (b) smaller total networks, (c) a smaller proportion of non-kin connections, (d) less politically diverse networks, and (e) less socioeconomically diverse networks.

Hypothesis 2 (H2): Compared to men, women will report (a) larger core networks, (b) smaller total networks, (c) a smaller proportion of non-kin connections, (d) less politically diverse networks, and (e) less socioeconomically diverse networks.

Hypothesis 3 (H3): Compared to more educated people, less educated individuals will report (a) smaller core networks, (b) smaller total networks, (c) a smaller proportion of non-kin connections, (d) less politically diverse networks, and (e) less socioeconomically diverse networks. 


\section{The Social Diversification Hypothesis}

A critical implication of widespread Internet use has been the potential to mitigate or exacerbate inequalities in social capital. Mesch $(2007,2011,2017)$ originally proposed the SDH to explain Internet use based on social positioning. The SDH predicts that Internet use provides disadvantaged groups the opportunity to overcome society's structural barriers that often keep them isolated in homogenous networks with fewer resources. Mesch (2011) notes that disadvantaged groups "will use the Internet to expand their social circle and overcome existing physical and social barriers to information and association" (p. 321). Advantaged groups, however, have different motivations. These groups use the Internet more to nurture their existing relationships rather than to expand and diversify their networks (Mesch, 2011).

The basic predictions outlined in the SDH (Mesch, 2007, 2011, 2017) have been supported in several studies. For example, White adolescents were significantly more likely to report more strong ties in their SNS networks than African American and Hispanic adolescents (Mesch, 2017). Additionally, White adolescents reported fewer bridging ties than Black and Hispanic individuals. In terms of the $\mathrm{SDH}$, the study proposed that these particular findings indicated Black and Hispanic adolescents were seeking to expand their networks through bridging ties while White adolescents were focused on maintaining their networks. In another study, Mesch (2011) explored how and why groups in Israel used the Internet and certain social applications (e.g., online communities, weblogs, e-mail, and SNS) for network expansion or maintenance. He found that Israeli Jews and immigrants from the former Soviet Union were more likely to report using the Internet for maintaining social ties than did a disadvantaged minority (i.e., Arab Israelis). Arab Israelis, in contrast, were more likely than the other two groups to report using the Internet to expand their social ties by meeting new people in social applications like online chat rooms and SNSs. Other researchers have reported results consistent with the SDH based on race and education among adults in the U.S. For example, Gonzales (2015) observed that Blacks and Latinos, as well as people with less education, were more likely to have weak-tie (i.e., bridging) exchanges online compared to Whites, Asians, and more educated individuals.

In sum, prior research testing the SDH has supported the prediction that disadvantaged groups are motivated to use the Internet to expand their networks, whereas advantaged groups use it to maintain their networks (Gonzales, 2015; Mesch, 2007, 2011, 2017; Mesch \& Talmud, 2010). The relationship between Internet use and users' social networks that lie at the heart of the outcomes predicted by the $\mathrm{SDH}$, however, require further consideration. The present study heeds Mesch's (2011) call for "further studies addressing more diverse groups" (p. 318). It also offers a more direct test of the SDH's predicted outcomes by examining differences in network structure (i.e., network size and diversity) in relation to Internet and SNS use among key demographic groups. Rather than focusing on motivations for using the Internet, we consider the implications of Internet use for users' social network composition. We believe that by moving beyond motivations, this study offers insights about whether the distinct Internet use behavior of advantaged and disadvantaged groups outlined in the SDH are manifested in observable differences in social network structure (Mesch, 2011). 
If the SDH (Mesch, 2007, 2011, 2017) functions as proposed, then it is reasonable to conclude there should be differences in network composition based on Internet use, SNS use, and non-use. In other words, inequalities in network size and diversity stemming from group affiliation should be smaller, non-existent, or even reversed among Internet users relative to non-users and SNS users relative to Internet users. Following the SDH (Mesch, 2007, 2011, 2017), we predict that differences in network size (i.e., core and total) and diversity (i.e., proportion of nonkin, perceived political diversity, socioeconomic diversity) based on race, sex, and education will be moderated by Internet use and SNS use. The largest differences-or most inequality -in network size and diversity stemming from race, sex, and education should exist among people who do not use the Internet. Because SNSs are designed specifically to facilitate interaction with others (Ellison, Steinfield, \& Lampe, 2007; Valenzuela et al., 2009), we predict that network inequalities between advantaged and disadvantaged groups should be smallest among Internet users who also participate in an SNS. Finally, by virtue of potentially gaining access to others but not to the same extent as people who adopt social applications like SNSs, we predict that inequality among Internet users should fall somewhere between non-users and SNS users.

Hypothesis 4 (H4): Internet and SNS use will moderate the relationship between race and (a) core network size, (b) total network size, (c) proportion of non-kin connections, (d) network political diversity, and (e) socioeconomic diversity. The difference in core network size, total network size, non-kin connections, network political diversity, and socioeconomic diversity will be greatest among non-users, followed by Internet users, and smallest among Internet users who also participate in an SNS.

Hypothesis 5 (H5): Internet and SNS use will moderate the relationship between sex and (a) core network size, (b) total network size, (c) proportion of non-kin connections, (d) network political diversity, and (e) socioeconomic diversity. The difference in core network size, total network size, non-kin connections, network political diversity, and socioeconomic diversity will be greatest among non-users followed by Internet users and smallest among Internet users who also participate in an SNS.

Hypothesis 6 (H6): Internet and SNS use will moderate the relationship between education and (a) core network size, (b) total network size, (c) proportion of non-kin connections, (d) network political diversity, and (e) socioeconomic diversity. The association between education and core network size, total network size, non-kin connections, and network political diversity will be largest among non-users followed by Internet users and smallest among Internet users who also participate in an SNS.

\section{Method}

This study utilized cross-sectional data collected on behalf of the Pew Internet and American Life Project (2010). Telephone interviews with a nationally representative sample of 2,255 U.S. adults were conducted between October and November 2010. Random digit dialing was used to contact potential respondents and 
the sample was weighted to reflect the U.S. adult population. A detailed explanation of the sampling and weighting procedure has been provided by the Pew Research Center (2011).

\section{Respondents}

Respondents were slightly more likely to be female $(53.8 \%, n=1202)$ and, on average, were 54 years old $(M=54.12, S D=18.78)$. Respondents were predominantly White $(n=1843,82.5 \%)$ followed by Black or African American $(n=190$, $8.5 \%)$, mixed race $(n=48,2.1 \%)$, Asian or Pacific Islander $(n=45,2.0 \%)$, Native American/American Indian $(n=27,1.2 \%)$, other $(n=14, .6 \%)$, don't know $(n=8$, $.4 \%)$, and refused $(n=60,2.7 \%)$. More than one-third of the respondents $(39.1 \%)$ had completed college or greater education.

\section{Measures}

Network size and composition measures. The name generator approach employed in the General Social Survey (Marsden, 1987; McPherson, Smith-Lovin, \& Brashears, 2006) was used to identify respondents' core network size, non-kin connections, perceived political diversity, and socioeconomic diversity. Respondents reported the first name of up to five confidants with whom they had discussed important matters during the preceding six months. The number of confidants reported by respondents was summed and used as the measure of core network size $(M=2.43, S D=1.34)$. After identifying the first name of confidants, respondents were asked to identify the nature of their relationship with each confidant using one or more of 11 response options. Sample responses included: spouse/partner; parent; brother/sister/sibling; co-worker; neighbor; friend; advisor. To determine respondents' non-kin connections, we first summed the number of confidants who were family members (i.e., spouse, parent, sibling, child, or other family member). This value was then divided by core network size and subtracted from $1(M=.36$, $S D=.38$ ). Readers should note that in dividing the sum of participants' non-kin connections by core network size, this measure accounts for differences in the size of respondents' core networks. Values for this measure should be interpreted as the proportion of each respondent's core network composed of non-kin connections.

Respondents then reported their perceptions of the political ideology of each core network member on a five-point scale ranging from "very conservative" (1) to "very liberal" (5). The difference in political ideology scores for each pair of confidants in a respondent's network were first computed. The absolute value for each pair-wise difference in confidants was then identified and the mean perceived political diversity for the respondent's network was calculated $(M=1.15, S D=.99)$. Perceived political diversity scores account for the size of each respondent's core network and reflect how ideologically diverse a respondent perceived his or her core network to be with larger values indicating greater perceived political diversity.

The socioeconomic diversity of respondents' networks was measured using the social network position generator approach (Lin \& Erickson, 2008; Lin \& Dumin, 1986). Respondents were given a list of 22 different occupations and asked to indicate whether they knew anyone holding each occupation. Sample occupations included nurse, farmer, lawyer, middle-school teacher, full-time babysitter, 
janitor, personnel manager, hairdresser, bookkeeper, production manager, operator in a factory, and computer programmer. We created a socioeconomic diversity index by summing all known positions $(M=9.74, S D=4.88)$. Values for this measure can range from 0 to 22 with larger scores indicating that respondents' social network contained greater socioeconomic diversity. To clarify, perceived political diversity was based on participant core networks while socioeconomic diversity was based on total networks.

To measure respondents' total network size, the scale-up method was applied (McCarty, Killworth, Bernard, Johnsen, \& Shelley, 2001; McCormick, Salganik, \& Zheng, 2010). Respondents were given a series of 12 first names (e.g., John, Jane, Robert, Sally) and asked how many people they know with each of the names. The scale-up method involves using the prevalence of each name in the American population in order to provide an estimate of the total number of people known by a respondent (McCarty et al., 2001). The mean total network size for respondents in our sample was 645 people (median $=489.31, S D=666.90$ ). One individual was excluded from the analyses due to reporting a total network size that was more than 45 standard deviations greater than the mean. After excluding this outlier, total network size remained positively skewed (skew $=4.08$ ). In order to address this issue, total network size was square-root transformed and the transformed variable (skew $=.77$ ) was used in analyses.

Internet use. Internet use was measured using two items that asked participants whether they use the Internet at least occasionally and if they use e-mail. Individuals who did not respond affirmatively to at least one of these two items were placed into the non-user group $(n=448)$. Those who reported using the Internet or e-mail were then separated by whether they reported using Facebook and MySpace. Participants who used either of these SNSs at least once per week were placed in the SNS group $(n=725)$. We chose one use per week as the cut-off for minimum SNS use in an attempt to identify regular users. Finally, individuals who used the Internet but not Facebook nor MySpace were included in the Internet user category $(n=1062){ }^{1}$

Demographic characteristics. Respondents were asked to report their race, sex, and education. Whites $(n=1857 ; 82.4 \%)$ were coded as 1 and all other races $(n=330 ; 14.6 \%)$ were coded as 0 , with the exception of those who indicated "don't know" or refused to answer the question whom were coded as missing. Sex was coded as 0 for male $(n=1041,46.2 \%)$ and 1 for female $(n=1214,53.8 \%)$. Education was measured by asking respondents to report the last grade or class they completed. Respondents were then grouped into one of seven categories ranging from none or grades 1-8 (1) to post-graduate training/professional school after college (7) $(M=4.80, S D=1.64)$. Finally, age $(M=54.12, S D=18.78)$ was included in our analyses as a control variable due to its importance in previous studies of the SDH (e.g., Mesch, 2017) as well as in Internet and SNSs adoption (Zickuhr \& Madden, 2012). The preceding demographics are unweighted; however, the remainder of the analyses conducted to test the hypotheses used weighted data. 


\section{Results}

In order to test our predictions, we ran five regression analyses (i.e., one for each dependent variable). Given our goal of testing interaction effects, we entered variables in blocks and mean-centered all demographic predictor variables (see Aiken \& West, 1991, Chapter 7). The first block of each regression analysis included a mean-centered age variable as a control. Mean-centered variables for race, sex, education level, and age were entered in the second block, followed by two dummy-coded variables reflecting Internet use status in the third block, and finally, interaction terms between the dummy-coded Internet use variables and the demographic variables in the fourth block. This approach resulted in four models for each dependent variable.

Given that our hypotheses were focused on how Internet non-users differ from Internet users, and how Internet users differ from Internet plus SNS users, Internet users were the reference group. The non-users dummy variable, therefore, reflected the comparison between non-users (coded 1) and Internet users (coded 0); the SNS dummy variable reflected the comparison between Internet users (coded 0) and Internet plus SNS users (coded 1). Statistically significant interactions indicated that the relationship between a demographic predictor variable and a network outcome variable was significantly different between Internet users (the reference category) and non-Internet users or SNS users. The results for all analyses have been summarized in Table 1.

\section{Inequality in Personal Social Networks}

Hypothesis 1 predicted that non-Whites would report (a) smaller core networks, (b) smaller total networks, (c) a smaller proportion of non-kin connections, (d) less politically diverse networks, and (e) less socioeconomically diverse networks. As shown in Table 1, race was a significant predictor of core network size, such that Whites reported significantly larger core networks than non-Whites. Hypothesis H1a was supported. Race was not a significant predictor of total network size, proportion of non-kin connections, perceived political diversity, or socioeconomic diversity. Hypotheses 1b,1c, 1d, and 1e were not supported.

Hypothesis 2 predicted that women would report (a) larger core networks, (b) smaller total networks, (c) a smaller proportion of non-kin connections, (d) less politically diverse networks, and (e) less socioeconomically diverse networks. Sex was a significant predictor of core network size, total network size, and proportion of non-kin connections. Men reported smaller core networks, but larger total networks and a greater proportion of non-kin connections. Hypotheses $2 \mathrm{a}, 2 \mathrm{~b}$, and 2c were supported. Sex did not predict perceived political diversity or socioeconomic diversity. Hypotheses $2 \mathrm{~d}$ and $2 \mathrm{e}$ were not supported.

Hypothesis 3 predicted that less educated individuals would report (a) smaller core networks, (b) smaller total networks, (c) a smaller proportion of non-kin connections, (d) less politically diverse networks, and (e) less socioeconomically diverse networks. Education was a significant predictor of core network size, total network size, non-kin connections, perceived political diversity, and socioeconomic diversity. Respondents with lower levels of education reported smaller core networks and smaller total networks than more educated individuals. Likewise, 
less educated individuals had fewer non-kin connections, less perceived political diversity, and less socioeconomic diversity in their networks. Hypotheses 3a-3e were supported.

\section{Internet Use and Network Inequality}

Hypothesis 4 predicted that Internet use would moderate the relationship between race and (a) core network size, (b) total network size, (c) non-kin connections, (d) perceived political diversity, and (e) socioeconomic diversity such that network differences related to race would be greatest among non-users followed by Internet users and smallest among Internet plus SNS users. The interaction between the no-Internet dummy-coded variable (non-users $=1$; Internet users $=$ 0 ) and race was significant for perceived political diversity. Decomposing this interaction showed that among Internet non-users, Whites reported significantly more perceived political diversity in their core networks than non-Whites $(\beta=.26$, $t=3.33, p=.001)$. Among Internet users, however, Whites reported significantly less perceived political diversity in their core networks than non-Whites $(\beta=$ $-.08, t=-2.17, p=.031$ ). This pattern of findings was consistent with Hypothesis $4 \mathrm{~d}$. Following the SDH, the relationship between inequality in perceived political diversity and race was reversed among Internet users relative to non-users. In other words, whereas network political diversity was greater among non-users who were White, it was also greater among Internet users who were not White. As Table 1 indicates, no other significant interactions were found between race and Internet use for the remaining network factors. Hypotheses $4 a, 4 b$, $4 c$, and $4 \mathrm{e}$ were not supported.

Hypothesis 5 predicted that Internet use would moderate the relationship between sex and (a) core network size, (b) total network size, (c) non-kin connections, (d) perceived political diversity, and (e) socioeconomic diversity such that network differences related to sex would be greatest among non-users followed by Internet users and smallest among Internet plus SNS users. As Table 1 indicates, no significant interactions were reported for sex and Internet use on network factors. Hypotheses 5a-5e were not supported.

Hypothesis 6 predicted that Internet use would moderate the relationship between education and (a) core network size, (b) total network size, (c) non-kin connections, (d) perceived political diversity, and (e) socioeconomic diversity such that network differences related to education would be greatest among non-users followed by Internet users and smallest among Internet plus SNS users. The interaction between the no-Internet dummy-coded variable (non-users $=1$; Internet users $=0$ ) and education was significant for core network size and perceived political diversity. Decomposing these interactions showed that among Internet users, education was positively and significantly associated with core network size $(\beta=$ $.17, t=4.63, p<.001)$ and perceived political diversity $(\beta=.17, t=3.49, p=.001)$. Among Internet non-users, education was not significantly associated with core network size $(\beta=-.00, t=-0.05, p=.977)$, nor perceived political diversity, $(\beta=-.03$, $t=-0.37, p=.713)$. These findings were inconsistent with H6a and H6d. Inequality in core network size and perceived political diversity related to education was greater among Internet users, but no relationship existed between education and these two variables among non-users. 
Additionally, the interaction between the Internet plus SNS dummy-coded variable (Internet plus SNS users $=1$; Internet users $=0$ ) and education was significant for total network size and socioeconomic diversity. Decomposing these interactions showed that among Internet users, education was positively associated with socioeconomic diversity $(\beta=.12, t=3.55, p<.001)$; however, it was not associated with total network size $(\beta=.01, t=0.33, p=.743)$. Among SNS users, education was also significantly associated with socioeconomic diversity $(\beta=.32, t=$ $9.35, p<.001)$ and total network size $(\beta=.18, t=5.19, p<.001)$. Again, these findings were inconsistent with $\mathrm{H} 6 \mathrm{~b}$ and H6e. The pattern of relationships indicate that inequality in total network size and socioeconomic diversity related to education was greater among Internet users who also used an SNS than among respondents who used only the Internet.

\section{Post-hoc Analyses}

We re-ran analyses with Asian or Pacific Islanders removed from the nonWhite demographic category and combined with Whites. This allowed us to address observed differences in the socioeconomic status of Asian or Pacific Islanders compared to Blacks and Hispanics. The results were principally the same as when Asian or Pacific Islanders were combined with non-Whites with two key exceptions. First, the interaction between SNS use and education on total network size (H6b) became non-significant. Second, the interaction between non-use and race on socioeconomic diversity $(\mathrm{H} 4 \mathrm{e})$ became significant. Given that the results were largely the same, we kept Asian or Pacific Islanders in the original non-White category, which we believe most closely reflects the original intent of the SDH.

\section{Discussion}

The goal of this project was to test the core outcomes predicted by the SDH (Mesch, 2007, 2011, 2017). Namely, that Internet and SNS use can help mitigate structural inequalities between demographic groups in terms of their social networks. In order to do so, we used a dataset from 2010 in a novel way that allowed us to test social network differences between traditionally advantaged and disadvantaged groups who do not use the Internet, those who do use the Internet, and those who use both the Internet and SNSs. In the following paragraphs we describe the implications of our key findings.

\section{Network Inequality and Internet Use}

The SDH (Mesch, 2007, 2011, 2017) makes predictions about the role of the relationship between Internet use and long-standing inequalities in access to social resources. It was initially applied as a way to understand Internet use motivations among ethnic minorities in Israel (Mesch, 2007). The present study helps fill a gap in SDH research by evaluating the proposed outcomes of the SHD regarding how Internet use is related to network-based inequalities. It helps extend the SDH to new areas of disadvantage (i.e., sex and education) and offers a test of its theoretical implications by evaluating social network differences based on one's level of Internet access. 


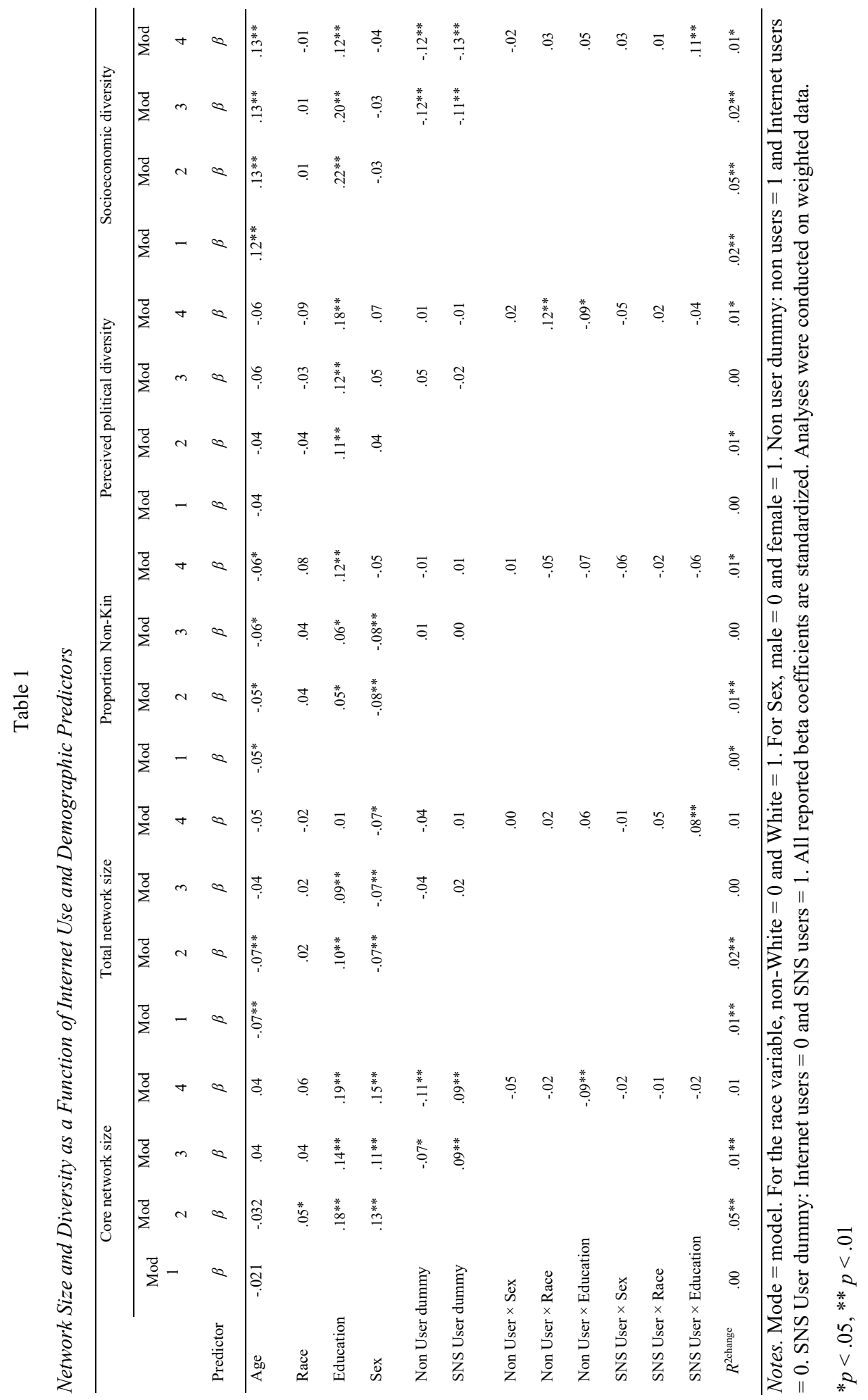


The results showed that the relationships between education and network size and diversity varied as a function of Internet and SNS use. The trends in these results, however, were in the opposite direction of what was predicted. The relationships between education and core network size as well as perceived political diversity were not significant for Internet non-users. Among Internet users, however, the relationships between education and both core network size and perceived political diversity were positive and significant. These findings showed that among Internet users, higher educated individuals had both a greater number of, and more diverse, bonding ties. Similarly, the associations between education and both total network size and socioeconomic diversity were significantly larger among SNS users than Internet-only users. The results suggest that SNS users increased their bridging ties in the form of larger and more socioeconomically diverse networks compared to Internet-only users. Taken together, these findings suggest that Internet and SNS use may allow people with relatively greater levels of education to expand the size and diversity of both their core networks (bonding ties) and total networks (bridging ties; Granovetter, 1973). Another important implication of the findings is that Internet-only use might be more applicable to bonding ties whiles SNS use is more applicable to bridging ties, which provides a new level of detail about how Internet use influences network size and diversity.

The interactions observed in this study largely contradict previous SDH findings (Gonzales, 2015; Mesch, 2007; 2011, 2017; Mesch \& Talmud, 2010; Smith, 2013). Contrary to the SDH (Mesch, 2007, 2011, 2017), use of the Internet and Internet plus SNSs on the whole did not help expand the networks of disadvantaged groups, but rather were associated with greater levels of inequality. Mesch (2011) argued this could be due to the "stratification hypothesis," which proposes that differential adoption rates of communication technologies reflect existing social inequities and may actually lead to a magnification effect. This is akin to the Matthew Effect, in which the rich get richer at a rate that makes the poor, poorer (Merton, 1968). What these findings might also indicate is that although disadvantaged groups are motivated to use the Internet to expand their networks, they are not actually achieving their goal. One reason for the discrepancy between the results of this study and previous research could be that much of the prior SDH research relied on self-report measures of motivations for use and did not directly capture the implications of Internet use for the composition of social networks (Mesch, 2007; 2011, 2017; Mesch \& Talmud, 2010; Smith, 2013). It could also be that the $\mathrm{SDH}$ is confined more narrowly to specific ethnic minority populations rather than racial minorities or other disadvantaged populations-despite some evidence to the contrary (Gonzales, 2015; Mesch, 2017).

Although a majority of our findings contradict the SDH, one finding aligned with the theory (Mesch, 2007, 2011, 2017). The significant relationship between race and perceived political diversity was reversed among Internet users relative to non-users. Whereas non-Whites who did not use the Internet reported less perceived political diversity in their core networks than White non-users, non-White Internet users actually reported greater political diversity than White Internet users effectively reversing the relationship between race and this form of network inequality. This finding could reflect the potential of Internet use to facilitate more diverse bonding connections (i.e., strong ties) among the core networks of tradi- 
tionally disadvantaged groups. Given the preponderance of results, however, this single finding should be interpreted cautiously. More broadly, readers should note that the blocks containing the interaction terms only explained a small amount of unique variance in the network measures. Even so, we believe these results are important and provide novel observations regarding the SDH and the implications of Internet use for social network size and diversity.

The fundamental assumption of the SDH (Mesch, 2007, 2011, 2017) is that disadvantaged groups will use the Internet and social applications to expand their networks while advantaged groups will use these tools for network maintenance. What the present study predominantly shows, however, is that Internet and SNS use are not associated with lower levels of inequality in network size and diversity for sex, and are associated only for race and perceived political diversity. Furthermore, the observed interactions involving education and key network factors showed that Internet and SNS use was associated with greater inequality rather than less inequality, thus contradicting a core prediction of the SDH in relation to education. Next, we discuss network inequalities related to race, sex, and education.

\section{Demographic Predictors of Network Inequality}

In addition to testing the key outcome predicted by the SDH, this study also offers a more contemporary assessment of inequalities in network resources between important demographic groups. The findings show that several social network disparities persist between traditionally advantaged and disadvantaged groups, while others appear to be shifting. Education proved to be the most salient and persistent demographic characteristic for explaining social network size and composition. Specifically, education was a significant predictor of each of the network factors explored in this study such that those disadvantaged individuals with less education also had smaller and less diverse networks. This finding aligns with prior research (Marsden, 1987). Education represents one of the most robust factors in determining one's social network size and composition and, therefore, is essential to addressing social network inequalities. Notably, education is the only demographic factor explored in this study over which people have some controlalbeit very limited, in some cases. The findings from this study underscore the potential benefits of expanding access to education. Beyond the tangible economic advantages, the results of this study suggest that greater educational opportunities could also potentially help yield more expansive access to social resources through larger and more diverse networks.

The findings for sex also reflected traditional inequalities, although the observed effect estimates tended to be smaller than for education. Women reported larger core networks than men. Men, however, reported larger total networks and a greater proportion of non-kin in their core networks than women. Again, these findings are consistent with prior research that showed women tend to face structural inequalities in social network size and composition (Marsden, 1987; Moore, 1990); however, they contradict more recent research that found a leveling of nonkin connections between men and women (McPherson et al., 2006). The implication of the findings reported in this study is that women appear to continue to face structural network inequalities that are likely tied to artificial constraints manufactured by an unequal social structure that privileges men in terms of income, jobs, 
and childcare obligations among other factors. In these terms, men have structural advantages toward achieving status positions that can in turn lead to larger networks composed of more non-kin connections (Moore, 1990).

In regard to race, the only significant difference between Whites and nonWhites was in core network size such that Whites reported significantly larger core networks than non-Whites. This finding aligns with previous research showing that Blacks and Hispanics both exhibit smaller networks than Whites (Marsden, 1987; McPherson et al., 2006). It is also important to note, however, that Whites and non-Whites did not differ in total network size or network diversity (i.e., proportion of non-kin, perceived political diversity, and socioeconomic diversity), which contradicts previous findings that showed these traditional network inequalities (Hogan, Hao, \& Parish, 1990; Lin, 2000; Marsden, 1987; McPherson et al., 2001; McPherson et al., 2006; Moore, 1990; Parks-Yancy et al., 2009). This finding might indicate that in some practical ways, race has become less of a factor in network inequality despite persistent structural disadvantages.

\section{Limitations}

One limitation of the current study was that the data were from a cross-sectional survey conducted approximately 10 years ago. Although the survey is somewhat dated and only provides a snapshot of the population in question, it offered several unique opportunities to conduct a robust test of the SDH. Because the survey was conducted with a nationally representative sample of U.S. adults, readers can be confident in the accuracy of the estimated relationships between demographic and network variables. Moreover, the survey included established measures of network size and diversity utilizing the name generator method and the scale-up method. These measures, however, are not without limitations. Specifically, the scale-up method uses names that appear to skew toward predominantly White names; however, race was not associated with total network size in our analysis as might be expected if this measure was biased. Finally, the dataset was limited in that it did not include comprehensive measures of Internet use types or motivations. The survey did, however, make it possible to distinguish SNS users from individuals who only use the Internet.

\section{Conclusion}

In sum, by testing network-related outcomes of Internet and SNS use on a national sample of U.S. adults, we believe we have advanced SDH research however modestly. The present study offers insight into the network inequalities faced by disadvantaged groups including non-Whites, women, and less educated individuals. Additionally, it offers a contrary view to the assumption that Internet and SNS use is essential to addressing inequality. In fact, this study suggests just the opposite: Internet and SNS use was associated with greater social network inequalities. To be sure, the SDH (Mesch, 2007, 2011, 2017) remains an important part of scholarly efforts to explain the social implications of Internet use and requires additional study to fully understand if and how the Internet can be used to overcome structural inequalities. One direction for future research of the SDH would be to explore how demographic groups' networks vary in terms of the pro- 
portion of Internet connections they maintain. Additionally, to more directly test the SDH, a future study should focus on change in network size and composition over time among disadvantaged relative to advantaged groups.

\section{Acknowledgements}

The authors thank the Pew Internet and American Life Project for making available the data used in this study.

\section{Declaration of Conflicting Interests}

The author(s) declared no potential conflicts of interest with respect to the research, authorship, and/or publication of this article.

\section{Funding}

The author(s) received no financial support for the research, authorship, and/or publication of this article.

\section{Endnote}

1. Twenty "smartphone dependent" Internet users were removed from the dataset prior to analysis due to the unique nature of this group. Smartphone dependents only had access to the Internet via their mobile phones. These individuals reported not using the Internet at least occasionally or sending email, but also reported using their mobile phones to connect to the Internet or send Email.

\section{References}

Aiken, L. S., \& West, S. G. (1991). Multiple regression: Testing and interpreting interactions. Newbury Park, CA: Sage.

Bourdieu, P. (1985). The social space and the genesis of groups. Information (International Social Science Council), 24, 195-220. https://doi. org/10.1177/053901885024002001

Campbell, K. E., Marsden, P. V., \& Hurlbert, J. S. (1986). Social resources and socioeconomic status. Social Networks, 8, 97-117. https://doi.org/10.1016/S03788733(86)80017-X

Coleman, J. S. (1988). Social capital in the creation of human capital. The American Journal of Sociology, 94, 95-120. http://www.jstor.org/stable/2780243

DiMaggio, P., \& Garip, F. (2011). How network externalities can exacerbate intergroup inequality. American Journal of Sociology, 116, 1887-1933. https://doi. org/10.1086/659653

Eagle, N., Macy, M., \& Claxton, R. (2010). Network diversity and economic development. Science, 328, 1029-1031. https://doi.org/10.1126/science.1186605

Ellison, N. B., Steinfield, C., \& Lampe, C. (2007). The benefits of Facebook "friends:" Social capital and college students' use of online social network sites. Journal of Computer-Mediated Communication, 12, 1143-1168. https://doi.org/10.1111/ j.1083-6101.2007.00367.x 
Garton, L., Haythornthwaite, C., \& Wellman, B. (1997). Studying online social networks. Journal of Computer-Mediated Communication, 3. https://doi. org/10.1111/j.1083-6101.1997.tb00062.x

Gonzales, A. L. (2015). Disadvantaged minorities' use of the Internet to expand their social networks. Communication Research, 44, 467-486. https://doi. org/10.1177/0093650214565925

Granovetter, M. S. (1973). The strength of weak ties. American Journal of Sociology 78, 1360-1380. https://doi.org/10.1086/225469

Hargittai, E. (2007). Whose space? Differences among users and non-users of social network sites. Journal of Computer-Mediated Communication, 13(1), 276-297. https://doi.org/10.1111/j.1083-6101.2007.00396.x

Hogan, D. P., Hao, L. X., \& Parish, W. L. (1990). Race, kin networks, and assistance to mother-headed families. Social Forces, 68, 797-812. https://doi.org/10.1093/ sf/68.3.797

Jamieson, K. H., \& Cappella, J. N. (2008). Echo chamber: Rush Limbaugh and the conservative media establishment. New York, NY: Oxford University Press.

Lin, Nan. 1982. Social resources and instrumental action. In P. V. Marsden and N, Lin (Eds.), Social structure and network analysis (pp. 131-45). Beverly Hills, CA: Sage.

Lin, N. (1999). Social networks and status attainment. Annual Review of Sociology, 25, 467-487. https://doi.org/10.1146/annurev.soc.25.1.467

Lin, N. (2000). Inequality in social capital. Contemporary Sociology, 29, 785-795. http://www.jstor.org/stable/2654086

Lin, N., \& Dumin, M. (1986). Access to occupations through social ties. Social Networks, 8, 365-385. https://doi.org/10.1016/0378-8733(86)90003-1

Lin, N., \& Erickson, B. H. (2008). Theory, measurement, and the research enterprise on social capital. In N. Lin \& B. H. Erickson (Eds.), Social capital: An international research program, (pp. 1-24). New York, NY: Oxford University Press.

Marsden, P. V. (1987). Core discussion networks of Americans. American Sociological Review, 52, 122-131. http://www.jstor.org/stable/2095397

McCarty, C., Killworth, P. D., Bernard, H. R., Johnsen, E. C., \& Shelley, G. A. (2001). Comparing two methods for estimating network size. Human Organization, 60, 28-39. https://doi.org/10.17730/humo.60.1.efx5t9gjtgmga73y

McCormick, T. H., Salganik, M. J., \& Zheng, T. (2010). How many people do you know?: Efficiently estimating personal network size. Journal of the American Statistical Association, 105, 59-70. https://doi.org/10.1198/jasa.2009.ap08518

McDermott, V. A. (1980). Interpersonal communication networks: An approach through the understanding of self-concepts, significant others, and the social influence process. Communication Quarterly, 28, 13-25. https://doi. org/10.1080/01463378009369378

McPherson, M., Smith-Lovin, L., \& Cook, J. M. (2001). Birds of a feather: Homophily in social networks. Annual Review of Sociology, 27, 415-444. https://doi. org/10.1146/annurev.soc.27.1.415

McPherson, M., Smith-Lovin, L., \& Brashears, M. E. (2006). Social isolation in America: Changes in core discussion networks over two decades. American Sociological Review, 71, 353-375. https://doi.org/10.1177/000312240607100301 
Mesch, G. S. (2007). Social diversification: A perspective for the study of social networks of adolescents offline and online. In: Kompetenzzentrum Informelle Bildung (eds) Grenzenlose Cyberwelt?. VS Verlag für Sozialwissenschaften https://doi.org/10.1007/978-3-531-90519-8_6

Mesch, G. S. (2011). Minority status and the use of computer-mediated communication: A test of the social diversification hypothesis. Communication Research, 39, 317-337. https://doi.org/10.1177/0093650211398865

Mesch, G. (2017). Race, ethnicity and the strength of Facebook ties. Journal of Youth Studies, 21, 575-589. https://doi.org/10.1080/13676261.2017.1396303

Mesch, G., \& Talmud, I. (2010). Wired youth: The social world of adolescence in the information age (Adolescence and society). New York: Routledge.

Moore, G. (1990). Structural determinants of men's and women's personal networks. American Sociological Review, 55, 726-735. http://www.jstor.org/stable/2095868

Mutz, D. C. (2002). The consequences of cross-cutting networks for political participation. American Journal of Political Science, 46, 838-855. http://www.jstor.org/ stable/3088437

Parks-Yancy, R., DiTomaso, N., \& Post, C. (2009). How does tie strength affect access to social capital resources for the careers of working and middle class African-Americans? Critical Sociology, 35, 541-563. https://doi. org/10.1177/0896920509103983

Pew Research Center. (2019). Social media fact sheet. Retrieved from https://www. pewresearch.org/internet/fact-sheet/social-media/

Pew Research Center. (2011). Social networking sites and our lives. [Data file and code book]. Retrieved from http://www.pewinternet.org/2011/06/16/socialnetworking-sites-and-our-lives/

Pew Research Center. (2018). Trends in party affiliation among demographic groups. Retrieved from http://www.people-press.org/2018/03/20/1-trends-in-party-affiliation-among-demographic-groups/

Portes, A., \& Jensen, L. (1989). The enclave and the entrants: Patterns of ethnic enterprise in Miami before and after Mariel. American Sociological Review, 54, 929-949. https://www.jstor.org/stable/2095716

Putnam R.D. (2000). Bowling alone: America's declining social capital. In L. Crothers, C. Lockhart (Eds), Culture and politics (pp. 223-234). New York, NY: Palgrave Macmillan.

Rains, S. A., \& Tsetsi, E. (2017). Social support and digital inequality: Does Internet use magnify or mitigate traditional inequities in support availability?. Communication Monographs, 84, 54-74. https://doi.org/10.1080/03637751.2016.1228252

Rogers, E. M., \& Kincaid, D. L. (1981). Communication networks: Toward a new paradigm for research. Free Press.

Smith, D. T. (2013). African Americans and network disadvantage: Enhancing social capital through participation on social networking sites. Future Internet, 5, 56-66. https://doi.org/10.3390/fi5010056

Stefanone, M. A., Kwon, K. H., \& Lackaff, D. (2012). Exploring the relationship between perceptions of social capital and enacted support online. Journal of Computer-Mediated Communication, 17, 451-466.

https://doi.org/10.1111/j.1083-6101.2012.01585.x 
Tsetsi, E., \& Rains, S. A. (2017). Smartphone Internet access and use: Extending the digital divide and usage gap. Mobile Media \& Communication, 5, 239-255. https://doi.org/10.1177/2050157917708329

Valenzuela, S., Park, N., \& Kee, K. F. (2009). Is there social capital in a social network site?: Facebook use and college students' life satisfaction, trust, and participation. Journal of Computer-Mediated Communication, 14, 875-901. https://doi. org/10.1111/j.1083-6101.2009.01474.x 